\title{
Comentario a Di Meglio, Gabriel Manuel Dorrego. Vida y muerte de un líder popular, Edhasa, Buenos Aires, 2014, 416 pág. ISBN 978- 987-628-297-0
}

\section{Comment to Di Meglio, Gabriel Manuel Dorrego. Vida y muerte de un líder popular, Edhasa, Buenos Aires, 2014, 416 pág. ISBN 978-987-628-297-0}

DANIEL SANTILLI

\section{Resumen}

El presente trabajo analiza el capítulo 8 del texto de Gabriel Di Meglio y se extiende en consideraciones acerca de otras partes del mismo libro. Se plantean preguntas al autor y se discute con él acerca de algunas aseveraciones. Al final se recogen respuestas de Gabriel Di Meglio.

Palabras clave: Manuel Dorrego - feliz experiencia - federalismo - sectores populares

\begin{abstract}
In this paper we analyse chapter 8 of Gabriel Di Meglio's book and advance some comments on others parts of the tome. We debate with him some of his claims and asked him a few questions. His answers are included in the final section.
\end{abstract}

Keywords: Manuel Dorrego - feliz experiencia - federalism - popular classes

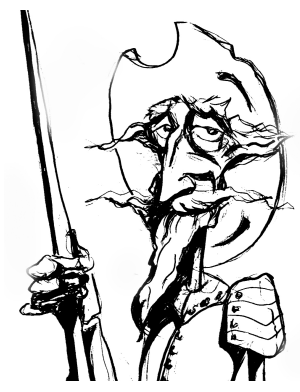

Recibido con pedido de publicación el 5 de octubre de 2016 Aceptado para su publicación el 30 de octubre de 2016 Versión definitiva recibida el 15 de noviembre de 2016

Daniel Santilli, Universidad de Buenos Aires, Instituto Ravignani, Argentina; e-mail: dvsantilli@gmail.com

Esta obra se publica bajo licencia Creative Commons. Atribución-NoComercial- (cc) EY-NC-SA CompartirIgual 4.0 Internacional

Santilli, Daniel "Comentario a Di Meglio, Gabriel. Manuel Dorrego. Vida y muerte de un líder popular", Prohistoria, Año XIX, núm. 26, dic. 2016, pp. 133-138. 
Me ha sido encargado leer y comentar el capítulo 8 del libro de Gabriel Di Meglio Manuel Dorrego. Vida y muerte de un líder popular. Trataré de ceñirme a ese fragmento, pero en algunos momentos abandonaré ese brete.

Gabriel Di Meglio se revela en este libro como un creador de climas. Intenta otorgarle, y lo logra, importancia, dentro del relato histórico, a aquello que proponía la microhistoria acerca de la relevancia de la narración, más allá de la investigación en concreto. $\mathrm{Y}$ es pertinente porque, dado el género elegido para el texto, la biografía se presta para ello, para la narración cronológica de aspectos de la vida del Coronel Dorrego, sin olvidar para nada el contexto en la cual se desarrolló.

El libro comienza con el relato del funeral de Dorrego en Buenos Aires, luego de restaurada la legalidad en diciembre de 1829. Más allá de la veracidad del relato, según los testigos que cita, el modo de presentar la narración es atrapante, como para que impulse al lector, después de leer ese párrafo inicial, a continuar leyendo el libro por cierto. Y esa puesta en escena se repite en el capítulo 10, el martirio.

Pero va la puesta en escena. Me permito leer el último párrafo cargado de dramatismo.

"Apenas puedo reconstruir lo que sigue. Lo sientan en el banquillo, junto a un corral. Le vendan los ojos con un pañuelo. Ninguno de los jefes se hace presente. Lavalle tampoco, espera en su habitación. Los soldados apuntan, una voz da la orden. Ya las descargas, las balas que le rompen el pecho. Manuel Dorrego ha muerto." (p. 351)

Es imposible no conmoverse. La oración inicial del párrafo, más allá de hacer referencia a la dificultad material del historiador de reconstruir verídicamente lo ocurrido, apela también a la imposibilidad de contarlo por la carga emocional del suceso.

Pero más allá de esta descripción, intento aquí hacer un análisis desde la ciencia histórica del texto, no de la técnica narrativa, que por cierto no deja de ser importante. $Y$, reitero, atrapante.

Di Meglio explica que la necesidad de una nueva biografía, agregada a las ya numerosas que existen sobre el personaje, se basa sobre todo en que cada generación escribe su propia versión de la historia, más motivada por la actualidad que por la estricta averiguación del pasado. O en todo caso, cada nueva investigación tiene que ver con el presente del investigador. Y las razones personales, siempre concurrentes en los historiadores cuando elegimos el objeto o el actor de nuestra investigación. Todo salpimentado con recuerdos familiares o personales, como nos tiene acostumbrado el autor desde su primer libro. 
El capítulo que me fue asignado es, junto con el 7, el del definitivo abandono de la carrera militar, la carrera abierta al talento, parafraseando a Hobsbawm, ${ }^{1}$ pero también a Tulio Halperín Donghi, ${ }^{2}$ que decía que esa era la trayectoria de todo miembro de la élite que pretendiese ascender en el Río de la Plata. En efecto, Dorrego, luego de su último exilio en la Banda Oriental, entiende que la paz promovida por Martín Rodríguez y Rosas puede incorporarlo como político, no ya como militar, porque su propuesta bélica no será efectiva ni viable. La élite quiere paz para los negocios.

En este capítulo, el 8, se demuestra que Manuel es mejor como político, e incluso como guerrero, que para los negocios. Y progresivamente será mejor político aún. La lectura de su viaje al norte parece demostrar eso. Si bien se supone que su desplazamiento es por negocios, la lectura que hace Di Meglio, basado en algunos testimonios, es que va a hacer política, "nacional" y continental. Va a entrevistarse y luego aliarse con Bustos e Ibarra. Significa que su apreciación de la política incluye ahora estos espacios, las provincias, antes minimizados desde su porteñismo. También el apoyo a los Treinta y tres orientales se puede leer desde la misma óptica. Por supuesto que desde otra mirada se puede observar como oportunismo, lo que no hace Di Meglio; el historiador juzga acciones, no es psicólogo. Ya sabemos, porque lo dice, que él simpatiza con el personaje, basado en su condición de líder de la plebe, en sus buenas relaciones con sus subalternos, con el pueblo raso. Sin embargo, muestra unos cuantos episodios desde los cuales es posible imaginar un cierto trato paternalista hacia la plebe. Reparte bienes y planazos.

Sus ambiciones "nacionales" pueden deducirse de su entrevista con Bolívar y de su deseo de conseguir una alianza para enfrentar al Imperio de Brasil, único espacio no republicano de Sud América. Bolívar, enemigo declarado del Antiguo Régimen, era un aliado predispuesto. Hay aquí una visión algo más profunda según Di Meglio, al intuir el inicio de la guerra. Me parece que no era la de Dorrego una lectura muy intrépida. Ya estaba en ciernes la guerra. Se había emprendido el camino sin retorno que llevaba al enfrentamiento con el Imperio.

La llegada al Congreso Constituyente como diputado por Santiago del Estero abre, a mi entender, la etapa más fecunda en lo político de su corta vida. Tal vez es el momento donde mejor se puede leer su pensamiento, sobre todo su accionar y su olfato político. Y porque parece que todo lo que proponen los unitarios encuentra su oposición. Por supuesto que fundada y muy bien

\footnotetext{
${ }^{1}$ HOBSBAWM, Eric La era de la revolución. 1789-1848, Crítica, Barcelona, 1997.

2 HALPERIN DONGHI, Tulio De la revolucion de independencia a la confederacion rosista, Vol. 3, Paidos, Buenos Aires, 1985. HALPERIN DONGHI, Tulio Revolución y Guerra. Formación de una élite dirigente en la Argentina criolla, Siglo XXI, Buenos Aires, 1972.
} 
fundada su opinión. Es un rasgo a pensar, si el oportunismo no forma parte del juego político, si aceptamos la corriente definición de la política como el arte de lo posible. En todo caso debe ser redefinido como olfato, sensibilidad, oído, todo aquello que quien quiera obtener apoyos en una sociedad como la que se estaba construyendo, basada en la legitimidad otorgada por la masa de los ciudadanos, debía poseer.

Su asunción del federalismo, mejor del confederacionismo, lo lleva a apoyar la destitución de un diputado santiagueño que desobedece a su gobernador. Está presente aquí el problema de la representación, tan caro a los estudios sobre historia política ¿los diputados son de la provincia o de la nación? Discusión abierta aún, con otros actores.

Pero no es fácil definir el federalismo y mantener la unidad del bloque federal, que además estaba en minoría. No hubo un proyecto de constitución federal para oponerle al proyecto unitario, estructurado y con mayoría. Di Meglio se pregunta, y coincidimos, ¿este es un déficit intelectual de Dorrego y de sus aliados? Por lo menos tres fracciones encuentra en el partido federal, antes popular; cuando se lo quiere llevar a nivel del conjunto de las provincias. Una primera, algunas provincias declaradas federales solo pretenden, que no es poco, compartir los ingresos aduaneros. Pero una fracción porteña, encabezada por los nuevos federales como Rosas y Anchorena, intentaba que cada provincia se mantenga con sus propios recursos, lo que significaba, como luego ocurrió, que Buenos Aires se apropiara de todos los recursos de su Aduana. Era el puerto de Buenos Aires la puerta de entrada y de salida prácticamente única de la futura Confederación.

Dorrego navega en ese mundo borrascoso interno, conformando la tercera facción del federalismo. Esto está muy cerca de la imagen que se forma Tulio Halperín Donghi, de su descolocación en el movimiento que él encarna.

El modelo de Dorrego y sus compañeros era el jeffersoniano, que limitaba al Estado central para mantener la soberanía de los estados y la igualdad, frenando el autoritarismo del poder central. Una especie de doble soberanía. Porque "La unidad tiende al absolutismo, a la monarquía" decía. Dejó entrever que incluía en el Estado federal a los indígenas como nación. No preveía su incorporación individual como ciudadanos, aquello que proclamó Castelli en el Alto Perú, y que buena parte de la élite liberal concedía entusiasmada. $\mathrm{O}$ sea, un nacionalismo basado en la restauración del virreinato, con los indígenas como otra nación.

Pero ese federalismo tenía un límite; rechazaba el de Artigas, Ramírez y Carreras, acérrimos enemigos de Buenos Aires y de él mismo, que tanto los combatió. Una muestra de su acendrado porteñismo. Sin embargo, no desmiente para nada que su inclinación hacia la plebe es similar en la forma a la del artiguismo. La diferencia está en que la plebe no estaba conformada igual. 
Su discurso se dirigía a los sectores subalternos urbanos y no a los "desposeídos rurales" orientales.

Su proyecto, como se ve, es político por sobre todo; no muestra Di Meglio que Dorrego tenga una posición tomada en la cuestión del sistema rentístico. Y digo rentístico y no económico, porque entiendo que nadie, todavía en ese tiempo, podía tener otra propuesta que la del librecambio. No creo que, como dice Nicolau, y cita Di Meglio, Dorrego estaba en el medio de dos facciones económicas que representaban intereses económicos diferentes.

Es decir, ya se vislumbra que toda la lucha facciosa tiene que ver con quién maneja los recursos de la aduana. ¿Sería una exageración decir que la historia del siglo XIX argentina, o de este lado del Río de la Plata, se podría reducir al manejo de los recursos de la Aduana? Visión demasiada simplificada que no me perdonarían los cultores de la historia política.

Sobre el pensamiento en ese tópico de Dorrego nada nos dice el autor y esa es mi pregunta. ¿nunca se expresó en ese sentido? Se podría pensar que, dado el federalismo que proponía, estaba más cerca de dejar librado a cada provincia a su propio recurso, tal como querían Rosas y los neofederales. Lo que lo haría mucho más porteño de lo que se entrevé en el capítulo que comento. De todos modos, porque no lo tenía, o porque no era conveniente darlo a conocer, no parece haber expresado su pensamiento en la materia. Esto, más allá de la pertenencia al grupo de labradores, según Di Meglio, porque era propietario de una chacra. Me permito dudar que sus intereses "de clase" pasen por tal pertenencia. Ya dijimos que su predicamento era más urbano que rural.

Su hora más memorable y su mayor acercamiento con la plebe se desarrolla durante el debate sobre la ciudadanía en el Congreso constituyente. Denuncia el retroceso de la facción unitaria, que cuando formaba parte del partido del orden promovió la ley de sufragio de 1821 y que ahora pretendía restringir el derecho a voto. Los argumentos de Dorrego son realmente impecables. Sin dudas, es el punto más alto de su discurso. Plantear que los dependientes pagan impuestos y consumen y no pueden influir en las elecciones es un argumento notable, de otro siglo, que además descoloca totalmente a sus contrincantes dejándolos parados en el espacio antipopular. Pero también encuentra su límite. Porque en definitiva él habla de igualdad de derechos, de oportunidades, limitadas en este caso a la ciudadanía.

Si lo trasladamos al plano económico social, el liberalismo debía asegurar la igualdad de oportunidades, la igualdad ante la ley (camino a recorrer, por cierto) pero nada decía de la de posición, parafraseando a François Dubet. $^{3}$ Su

\footnotetext{
${ }^{3}$ DUBET, François “Elegir para actuar", en Le monde diplomatique, 1 de marzo de 2016, pp. 12-13. DUBET, François Repensar la justicia social. Contra el mito de la igualdad de oportunidades, Siglo XXI Editores, Buenos Aires, 2011.
} 
lugar en la sociedad no le permitía proponer una igualación de las fortunas, es decir de posiciones. Si hubo algún proceso de disminución de la desigualdad o de mejora en el nivel de vida no fue un acto voluntario de la élite, ni de Dorrego.

\section{Una acotación fuera del capítulo mencionado}

José Carlos Chiaramonte, en una reseña para la revista $\tilde{\mathrm{N}}(14 / 01 / 15),{ }^{4}$ al poco tiempo de publicado el libro, se preguntaba por qué no movilizó sus apoyos populares para defenderse en 1829 , y se responde a sí mismo porque en realidad como miembro de la élite no podía traicionar a sus pares, su procedencia de clase no se lo permitió. Y deduce Chiaramonte que Dorrego no era un líder popular porque no había surgido de la misma plebe. Más allá de la discusión que puede generarse acerca del análisis de la procedencia de clase de un líder popular, este comportamiento es una constante entre los líderes populares. Le pasó a Rosas en 1852. Y tenemos casos más cercanos en nuestra historia, y la de América Latina. Me pregunto, y se lo traslado al autor, ¿ese era su límite? ¿No se animó a abrir la puerta a la plebe? ¿se trata de un límite de clase o de estrategia política? ¿no será que los lideres confían en sus fuerzas y su prestigio de manera tal que suponen que nadie se animará a enfrentarlos?

Es de recordar que este era un camino sin retorno, los que lo practicaron no volvieron, no consiguieron luego recomponer sus lazos con la élite. Le pasó a Artigas, le pasó a Rosas, a Güemes, para quedarnos solo en los contemporáneos.

Buenos Aires, julio de 2016

${ }^{4}$ CHIARAMONTE, José Carlos "Retrato de un líder federal y popular", en Revista N , 14 de enero de 2015. 